\title{
Features of Reduction of Th1, Th2 Lymphocytes Functions After Intoxication of Various Toxic Chemicals
}

\author{
Pavel F Zabrodsky* \\ Saratov Medical University, Russia \\ *Corresponding author: Pavel F Zabrodsky, Saratov Medical University “REAVIZ”, Saratov, Russia. \\ To Cite This Article: Pavel F Zabrodsky. Features of Reduction of Th1, Th2 Lymphocytes Functions After Intoxication of Various Toxic Chemicals. \\ Am J Biomed Sci \& Res. 2019 - 3(4). AJBSR.MS.ID.000698. DOI: 10.34297/AJBSR.2019.03.000698
}

Received: June 11, 2019 | Published: June 27, 2019

\begin{abstract}
Experiments on random-bred albino rats showed that organophosphorus compound (malathion) acute intoxication $\left(0.5 \mathrm{LD}_{50}\right)$ in the greater degree reduces function of Th1 lymphocytes and bound with them of delayed-type hypersensitivity (DTH) reaction and production IFN $\gamma$, in comparison with function of Th2 lymphocytes and synthesis of IL- 4 by them; the opposite effect is characteristic for methanol $\left(0.5 \mathrm{LD}_{50}\right.$; decreases Th2-lymphocytes function (IgG and IL-4 production) to a greater extent); acetonitrile and trichloromethane acute intoxications ( 0.5 LD ${ }_{50}$ ) invokes a reduction of functions of Th1 and Th2 lymphocytes and production of cytokines by them (IFN $\gamma$ and IL-4) equally.
\end{abstract}

Keywords: Toxic Chemical; Immunotoxity; Th1, Th2 Lymphocytes; Cytokines

\section{Introduction}

Toxic chemicals (TCh) may have a different effect on Th1, Th2 lymphocyte function, identifying features of the humoral and cellular immune response, leading to infectious complications and diseases [1-6]. It is interesting to study the effects of TCh (organophosphorus compounds, nitriles, alcohols and chlorinated hydrocarbons), widely used in industry and agriculture, on the activity of Th1, Th2 lymphocytes, which can cause acute poisoning in case of accidents at chemical plants and safety violations [2,3,7]. It should be noted that there is a possibility of using organophosphorus compounds (along with other chemical warfare agents) as chemical warfare agents for terrorist, criminal and military purposes, which can lead to mass destruction of people [2,3,8-10].

Th1 cells, participating in the implementation of the cellular immune response, producing IFN- $\gamma$. Th2 lymphocytes (in particular, synthesizing IL-4) are involved in the formation of humoral immune responses, contributing to the production by B lymphocytes (plasma cells) of immunoglobulins of the main classes (IgG1, IgA, IgE and IgD $[3,11]$. From the ratio Th1, Th2 type lymphocyte activity (their function) may depend on the likelihood of respectively viral or microbial infections $[3,4,11,12]$, also the formation of skin or respiratory hypersensitivity $[4,13,14]$. Thus, the activity of Th2-lymphocytes is associated with the synthesis of IgE, which provide respiratory manifestation of allergic reactions $[2-4,11,14]$.
Thus, knowing the characteristics of Th1 and Th2 lymphocyte TCh lesions, it is possible not only to predict the risk of development of cellular or humoral immunity, leading to various infectious complications and diseases, but also to make choices that are adequate to the nature of the immune status of the immunomodulators $[2-4,7,11,14]$.

\section{Aim of the study}

The aim of the study was to determine the types of dysfunction of Th1, Th2-lymphocytes and their production of cytokines, respectively, IFN- $\gamma$ and IL-4 in the formation of suppression of humoral and cellular immune reactions in acute intoxication with various toxic chemicals.

\section{Materials and Methods}

The experiments were performed on random-bred albino rats of both sexes weighing 180-240 g. TCh (malathion - MT - [0,0-Dimethyl-S- (1,2-dicarbethoxyethyl) dithiophosphate]; methanol - MTh, acetonitrile- AN and trichloromethane -TChM) (Sigma-Aldrich] was administered subcutaneously at a single dose of 0.5 LD

. $\mathrm{LD}_{50}$ of MT, MTh, AN and TChM for rats after subcutaneous administration was, respectively, 815,4 $\pm 28,0,8050,0 \pm 430,1750 \pm 95$ and $6010 \pm 615 \mathrm{mg} / \mathrm{kg}$. Immunity system indicators were evaluated 
by generally accepted methods in experimental immunotoxicology and immunology $[2,3,11]$ after administered of TCh (acute intoxication). The control group of rats was administered subcutaneously at a single dose of $0.25 \%$ aqueous solution $(1,0 \mathrm{ml})$ of dimethyl sulfoxide (DMSO). TCh was administered subcutaneously in $1.0-1.5 \mathrm{ml}$ of a $0.25 \%$ solution of DMSO. TCh was dissolved in DMSO, a $0.25 \%$ aqueous solution containing a toxicant was prepared.

The function of Th1 lymphocytes was determined by delayed-type hypersensitivity (DTH) reaction. The DTH was studied in animals by weight gain of the hind paw foot in \%. The resolving dose of RSBC $(5 \times 108)$ was administered under the aponeurosis of foot of the hind paw on 4 days after immunization, which was performed intraperitoneally almost simultaneously with the administered of TCh. The reaction of DTH was evaluated after $24 \mathrm{~h}[2,3,5,6]$.
The function of Th2 lymphocytes was investigated by the number antibody-forming cells (AFC) in the spleen, synthesizing IgG to sheep blood cells (RSBC), in the spleen on 8 days after intraperitoneally immunization $2 \times 108 \mathrm{RSBC}$ almost simultaneously with the administered of TCh) by indirect local hemolysis in the gel $[2,3,11]$.

The concentration of immunoregulatory cytokines IFN- $\gamma$ (\#MBS824935) and IL-4 (\# MBS2883072), proinflammatory cytokine IL-6 (\# MBS2885203)) [3,15] was examined in rat blood plasma, respectively, on 5 and 8 days after the first injection of TCh using kits (ELISA Kits MyBioSoure) in accordance with the manufacturer's instructions. Blood for research was taken from the retroorbital venous sinus. The data obtained were processed statistically using the Student's t-test. Differences between the parameters were considered reliable at $\mathrm{p}<0.05$.

\section{Results}

\begin{tabular}{|c|c|c|}
\hline Table 1: The effect of various toxic chemicals acute intoxication $\left(0.5 \mathrm{LD}_{50}\right)$ on the function of Th1 and Th2 lymphocytes in rats $(\mathrm{M} \pm \mathrm{m}, \mathrm{n}=\mathbf{8}-10)$ \\
\hline \multirow{2}{*}{ Toxic chemicals } & Th1 lymphocyte function & Th2 lymphocyte function \\
\cline { 2 - 3 } & DTH reaction, \% & AFC to RSBC (IgG), 10 \\
\hline Control & $32,5 \pm 1,0(\mathrm{n}=33)$ & $24,9 \pm 1,1^{*}(\mathrm{n}=30)$ \\
\hline Malathion & $14,3 \pm 1,6^{*}$ & $16,5 \pm 1,9^{*}$ \\
\hline Methanol & $23,4 \pm+2,5^{*}$ & $12,8 \pm 1,3^{*}$ \\
\hline Acetonitrile & $17,5 \pm 1,8^{*}$ & $14,0 \pm 4,5$ \\
\hline Trichloromethane & $21,3 \pm 2,2^{*}$ & $16,7 \pm 1,8^{*}$ \\
\hline
\end{tabular}

Under the influence of TCh (Table 1) - malathion, methanol, acetonitrile, trichloromethane - there was a decrease in the function of Th1 lymphocytes, assessed by the DTH reaction compared to the control level, respectively, in $2.27 ; 1.39 ; 1.86$ and 1.53 times $(p<0.05)$. The activity of Th2 lymphocytes after acute intoxication of MT, MTh, AN and TChM on day 8 after immunization of RSBC, estimated by the concentration of IgG (the number of AFC in the spleen), decreased, respectively, by $1.51 ; 1.95 ; 1.78$ and 1.49 times $(\mathrm{p}<0.05)$.

Thus, the parameters characterizing various immune reactions and the associated functions of Th1 and Th2 lymphocytes, under the action of MT decreased in 2.27 and 1.51 times, respectively, and with MTh acute intoxication - in 1.39 and 1.95 times, AN acute intoxication - in 1.86 and 1.78 times, with TChM acute intoxication
- in 1.53 and 1.49 times, respectively. This suggests that under the influence of the organophosphorus compound (MT) acute intoxication the greater degree reduces functions of Th1 lymphocytes, MTh causes a reduction of mainly Th2 lymphocytes activity, and AN and TChM acute intoxications the Th1 and Th2 lymphocytes are equally impaired.

The revealed features of the lesion of various TCh of Th1- and Th2 lymphocytes functions is confirmed by a study of the concentration of cytokines in the blood of rats (Table 2). After acute intoxication of organophosphorus compound (MT), there was decrease of the concentrations of IFN- $\gamma$ and IL-4, respectively, in 2.21 and 1.65 times $(\mathrm{p}<0.05)$, after MTh acute intoxication - in 1.46 and 2.05 times ( $\mathrm{p}<0.05)$, AN -1.98 and 2.22 times $(\mathrm{p}<0.05)$, after exposure of TChM - in 2.72 and 1.80 times $(\mathrm{p}<0.05)$, respectively.

\begin{tabular}{|c|c|c|c|}
\hline Toxic chemicals & IFN- $\gamma$ & IL-4 & IFN- $\gamma /$ IL-4 \\
\hline Control & $998 \pm 35(n=33)$ & $160 \pm 9(n=30)$ & $6,2 \pm 0,2$ \\
\hline Malathion, & $451 \pm 50^{*}$ & $97 \pm 11^{*}$ & $4,6 \pm 0,4^{*}$ \\
\hline Methanol & $685 \pm 69 *$ & $78 \pm 8^{*}$ & $8,8 \pm 0,7^{*}$ \\
\hline Acetonitrile, & $505 \pm 51^{*}$ & $72 \pm 10^{*}$ & $7,0 \pm 0,6$ \\
\hline Trichloromethane & $581 \pm 60^{*}$ & $89 \pm 9^{*}$ & $6,5 \pm 0,7$ \\
\hline
\end{tabular}

An increase in the IFN- $\gamma / \mathrm{IL}-4$ ratio characterizes a decrease of the functional activity of Th2 lymphocytes as compared with the function of Th1 cells, and a decrease in this ratio indicates a greater suppression of the activity of Th1 lymphocyte lymphocytes 
compared to Th2 cells [2,3]. We found that the ratio of IFN- $\gamma /$ IL-4 in acute intoxication with MT, MTh, AN and TChM was $4.6 \pm 0.4$ $(\mathrm{p}<0.05) ; 8.8 \pm 0.7(\mathrm{p}<0.05) ; 7.0 \pm 0.6$ and $6.5 \pm 0.7$, respectively (control $-6.2 \pm 0.2$ ). This confirms the results testifying about the features of lesion of Th1 and Th2 cell damage by various TCh.

\section{Discussion}

The main mechanisms of dysregulation of immunogenesis and the function of $\mathrm{T}$ and $\mathrm{B}$ immunity with organophosphorus compound (MT) acute intoxication are: changes in the redistribution of immunocytes between the organs of the immune system; violation of the cooperation of T-and B-lymphocytes; inhibition T-cell acetylcholinesterase, natural killer cells (NK) acetylcholinesterase and acetylcholinesterase of cells of antibody-dependent cellular cytotoxicity (ADCC); effect on cholinergic receptors of immunocompetent cells of high acetylcholine concentrations; immunosuppressive effect of corticosteroids [2,3,16-18].

The immunotoxic effect under the action of methanol mainly associated with the reduction of IgG production (Th1 and B cells functions), is also associated with the suppression of B lymphocyte function due to a violation of folic acid metabolism, the immunosuppressive effect of corticosteroids, the initiation of immunocyte lipid peroxidation. It should be noted that the immunotoxic effect of methanol is predominantly associated with the action of metabolites of MTh - formaldehyde and formic acid [1,2,19]. Th2 lymphocytes are probably more sensitive to the highly toxic metabolites of biotransformation of methanol formaldehyde and formic acid [1,2].

An important role in the implementation of the immunotoxicity of AN is played not so much by the toxicant as its toxic metabolites, in particular hydrogen cyanide. It is cyanide by inhibiting component a3 of cytochrome-c-oxidase of the system of enzymes of tissue respiration of mitochondria of immunocompetent cells, which determines the main immunotoxic effect of AN. It should be noted that hydrogen cyanide during the metabolism of AN enters the system of tissue respiration of mitochondria of cells of the lymphoid organs within a few hours (up to a day). In addition, AN inhibits of T lymphocytes acetylcholinesterase, NK and ADCC cells acetylcholinesterase (to a lesser extent than organophosphorus compound) $[2,20]$.

In the mechanism of damage to the immune system after TChM acute intoxication, activation of the hypothalamic-pituitary-adrenal system (the action of corticosteroids) $[2,3,16,17]$, initiation of lipid peroxidation and inhibition of acetylcholinesterase T lymphocytes, NK and ADCC cells plays a significant role [2].

\section{Conclusion}

Thus, the various toxic chemicals acute intoxication (in equiletal dose $0.5 L_{50}$ ) can lead to relatively greater damage to Th1 or Th2 lymphocytes, as well as disrupt their function equally. Organophosphorus compound (malathion) acute intoxication in the greater degree reduces function of Th1 lymphocytes and production IFN $\gamma$, in comparison with of Th2 lymphocytes function and synthesis of IL-4 by them; the opposite effect is characteristic for metha- nol (decreases Th2 lymphocytes function and IL-4 production to a greater extent); acetonitrile and trichloromethane acute intoxications invokes a reduction of function of Th1 and Th2 lymphocytes and production of cytokines by them (IFN $\gamma$ and IL-4) equally.

\section{References}

1. PF Zabrodskii (1998) Immunotropic properties of poisons and drugs. Saratov. Saratov State Medical University, Russai, pp.213.

2. Zabrodskii PF, Mandych VG (2007) Immunotoxicology of xenobiotics. Saratov Military Institute of Biological and Chemical Safety, Russai. pp. 420 .

3. PF Zabrodskii (2016) Immunotoxicology of organophosphorus compounds. Saratov, Russai. pp. 289.

4. Kimber I (1996) Induced Hypersensitivity. In: Experimental Immunotoxicology. RJ Smidowicz, et al. (Eds.) Boca Raton, New York, London, CRC Press, Tokyo, pp. 391-417.

5. Zabrodskii PF (2019) The effect of ethylene trichloride chronic intoxication on immune responses, function of Th1 and Th2 lymphocytes and blood cytokine concentrations. Acta Scientific Microbiology 2(4): 80-83.

6. Zabrodskii PF (2019) The effect of dichloethane subacute intoxication on cellular, humoral immune reactions and the content of cytokines in the blood. Acta Scientific Microbiology 2(5): 11-14.

7. PF Zabrodskii (2002) Influence of xenobiotics on immune homeostasis. In: General toxicology, BA Kurlyandsky, et al. (Eds.) Medicine pp. 352384.

8. McManus J, Huebner KM (2005) Vesicants. Critical Care Clinics 21(4): 707-718.

9. Saladi RN, Smith E, Persaud AN (2006) Mustard: a potential agent of chemical warfare and terrorism. Clinical and Experimental Dermatology 31(1):1-5

10. Hefaxi M, Maleki M, Mahmoudi M, Tabatabaee A, Baladi Mood M (2006) Delayed complications of sulfur mustard poisoning in the skin and the immune system of Iranian veterans 16-20 years after exposure. International Journal of Dermatology 45(9): 1025-1031.

11. Male D, Brostoff J, Roth D, Roitt I (2006) 'Immunology, ( $7^{\text {th }}$ edn), Elsevier pp. 563.

12. Asquith B, Zhang Y, Mosley AJ, de Lara CM, Wallace DL, et al. (2007) In vivo $\mathrm{T}$ lymphocyte dynamics in humans and the impact of human T-lymphotropic virus 1 infection. Proceedings of the National Academy of Sciences of the USA 104(19): 8035-8040.

13. Corsini E, Kimber I (2007) Factors governing susceptibility to chemical allergy. Toxicology Letters 168(3): 255-299.

14. Hsu HY, Lin BF, Lin JY, Kuo CC, Chiang W (2013) Suppression of allergic reactions by dehulled adlay in association with the balance of TH1/ TH2 cell responses. Journal of Agricultural and Food Chemistry 51(13): 3763-3769.

15. Becker KL, Nylén ES, White JC, Müller B, Snider RH (2004) Clinical review 167: Procalcitonin and the calcitonin gene family of peptides in inflammation, infection, and sepsis: a journey from calcitonin back to its precursors. Journal of Clinical Endocrinology and Metabolism 89(4): 1512-1525.

16. Pruett S, Lapointe JM, Reagan W, Lawton M, Kawabata TT (2008) Urinary corticosterone as an indicator of stress-mediated immunological changes in rats. J Immunotoxicology 5(1):17-22.

17. Pruett SB, Fan R, Zheng Q, Myers LP, Hebert P (2003) Modeling and predicting immunological effects of chemical stressors: characterization of a quantitative biomarker for immunological changes caused by atrazine and ethanol. Toxicological Sciences 75(2): 343-354. 
18. Zabrodskil PF (1993) The mechanisms of the immunotropic effects of organophosphorus compounds. Bulletin of Experimental Biology and Medicine 116(2): 181-183

19. Parthasarathy NJ, Kumar RS, Devi RS (2005) Effect of methanol intoxication on rat neutrophil functions. Journal of Immunotoxicology 2(2): $115-121$
20. Zabrodskii PF, Gromov MS, Maslyakov VV (2014) Changes in immunity parameters and blood cytokine concentrations after chronic nitrile acrylate intoxication. Bulletin of Experimental Biology and Medicine 158(2): 238-241. 